\title{
PEMANFAATAN SITUS PENINGGALAN SEJARAH DI KABUPATEN BONDOWOSO SEBAGAI PENGEMBANGAN SUMBER BELAJAR DI SEKOLAH LANJUTAN TINGKAT ATAS DI KABUPATEN BONDOWOSO
}

\author{
Tantri Raras Ayuningtyas \\ Dosen Pendidikan Sejarah IKIP PGRI Jember \\ Email: mandaeggy@gmail.com \\ Anis Syatul Hilmiah \\ Dosen Pendidikan Sejarah IKIP PGRI Jember \\ Email: anisa_hilmiah@yahoo.com \\ Rina Rohmawati \\ Dosen Pendidikan Sejarah IKIP PGRI Jember \\ Email: rina.manis1@gmail.com
}

\begin{abstract}
Abstrak
Peninggalan kebudayan megalitikum yang tersebar di Bondowoso ini berupa menhir, dolmen, sarkofagus, kubur batu, batu kenong, pelinggih batu, ruang batu atau stonechamber dan arca. Kebudayaan megalitikum ini berlangsung hingga kini dengan memahami makna kepercayaan akan adanya hubungan antara mahluk yang hidup dan sudah mati. Dalam pembelajaran sejarah tingkat SMA, kebudayaan Megalitikum masuk dalam materi Sejarah Indonesia Kelas X dengan alokasi waktu 2 jam pelajaran tiap minggunya. Namun, pemblajaran dikelas yang ditawarkan kurang menarik dan menyenangkan. Penelitian ini bertujuan menjelaskan implementasi pemanfaatan situs peninggalan sejarah di Kabupaten Bondowoso sebagai pengembangan sumber belajar di SMA Negeri 2 Bondowoso dengan menggunakan kompetensi dasar tipologi hasil budaya Pra Aksara Indonesia termasuk yang berada di lingkungan terdekat. Pengembangan sumber belajar yang digunakan menggukan metode lawatan sejarah dan pembuatan buku teks sebagai bahan ajar tingkat SLTA dengan menggunakan model desain ADDIE dan diimplementasikan di sekolah menggunakan penelitian tindakan kelas, di kelas X IIS SMA Negeri 2 Bondowoso. Penelitian pengembangan ini diharapkan mampu meningkatkan pemahaman siswa dan meningkatkan hasil belajar siswa di kelas.
\end{abstract}

Kata kunci: situs megalitikum, pengembangan sumber belajar, pembelajaran sejarah.

\begin{abstract}
Megalithic cultural heritage scattered in Bondowoso this form of menhir, dolmen, sarcophagus, grave stone, kenong stone, pelinggih stone, stone room or stonechamber and statue. This megalithic culture lasted until now by understanding the meaning of belief in the existence of relationship between living and dead creatures. Learning history of high school level, Megalithic culture entered in the material of History of Indonesia Class $X$ with the allocation of time 2 hours of lessons per week but lesson classes offered less attractive and fun. This study aims to explain the implementation of the utilization of historical sites in Bondowoso District as the development of learning resources in SMA Negeri 2 Bondowoso by using basic competence 3.2 based on the culture typology of Pre-Literary Indonesia including those in the nearest neighborhood. The development of learning resources used used historical visit methodology and textbook making as a high school teaching materials using the ADDIE design model and implemented in school using classroom action research in XIIS SMA Negeri 2 Bondowoso. This development research is expected to improve students' understanding and improve student learning outcomes in the classroom.
\end{abstract}

Keywords: megalitikum site, learning source developing,historical learning 


\section{PENDAHULUAN}

Kabupaten Bondowoso secara geografis terletak di ujung sebelah timur pulau Jawa yang merupakan daerah tapal kuda Karisidenan Besuki. Bondowoso merupakan daerah dataran tinggi yang subur bagaikan "sebuah mangkuk" yang terletak di daerah pegunungan dengan alas dataran rendah di dalamnya. Selain itu, kawasan ini merupakan salah satu wilayah di Indonesia yang menyimpan riwayat sejarah purbakala dan peninggalan pra aksara berupa bangunan batu besar yang oleh ahli purbakala disebut kebudayaan megalitikum (Mashoed, 2004).

Peninggalan kebudayan megalitikum yang tersebar di Bondowoso ini berupa menhir, dolmen, sarkofagus, kubur batu, batu kenong, pelinggih batu, ruang batu atau stonechamber dan arca. Oleh masyarakat sekitar peninggalan megalitikum seringkali disebut pandhusa karena disamakan dengan kubur manusia. Kebudayaan megalitikum ini berlangsung hingga kini dengan memahami makna kepercayaan akan adanya hubungan antara mahluk yang hidup dan sudah mati (Soekmono, 2006).

Permendikbud No 59 Tahun 2014 tentang kurikulum 2013 menyatakan pembelajaran sejarah tingkat SMA, kebudayaan Megalitikum masuk dalam materi Sejarah Indonesia Kelas $\mathrm{X}$ dengan alokasi waktu 2 jam pelajaran tiap minggunya. Dengan demikian, guru dituntut lebih kreatif dan inovatif, sehingga ranah keterampilan, pengetahuan dan sikap dapat terpenuhi dalam setiap pembelajaran di kelas. Sehingga solusi yang ditawarkan untuk memperbaiki pendalaman materi pada siswa, tidak hanya mempelajari teori semata tetapi dengan memanfaatkan situs peninggalan sejarah yang terdapat di Bondowoso sebagai sumber belajar di SLTA/SMA yang dapat merangsang stimulus siswa dalam kegiatan belajar mengajar.

\section{METODE PENELITIAN}

Penelitian ini dilaksanakan pada siswa kelas X IIS Sekolah Menengah Atas Negeri 2 Bondowoso dan jenis penelitian yang digunakan adalah Penelitian Pengembangan atau dikenal dengan istilah Riset and Developmen (R\&D. Metode penelitian dan pengembangan adalah suatu metode penelitian yang digunakan untuk menghasilkan produk tertentu dan menguji keefektifan dari produk tersebut (Sugiyono, 2011). Penelitian ini bertujuan menghasilkan produk buku teks agar memudahkan guru memberikan bahan ajar kepada siswa saat mengikuti lawatan sejarah di lapangan. Model desain yang digunakan dalam pengembangan produk dalam penelitian ini adalah ADDIE (Analisis, Desain, Development, Implementasi, dan Evaluasi). Dalam membuat produk berupa buku teks, model desain ADDIE mudah diterapkan dimana proses yang digunakan bersifat sistematis dengan kerangka kerja yang jelas dalam menghasilkan produk 
yang efektif, kreatif, dan efisien (Reuser $\&$ desain ADDIE adalah sebagai berikut: Dempsey, 2007). Adapun alur penelitian

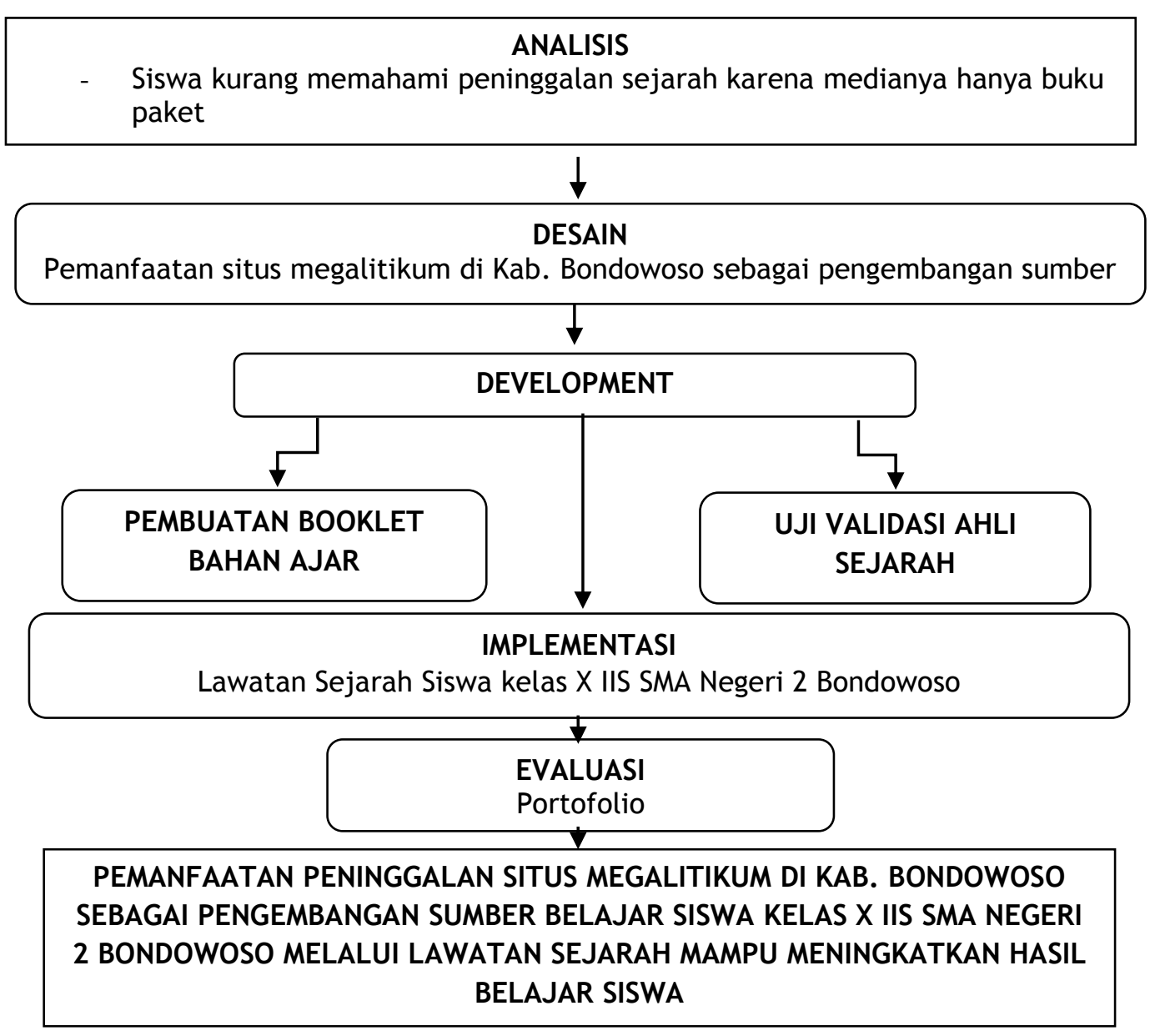

\section{Gambar 1. Alur Desain ADDIE}

\section{HASIL DAN PEMBAHASAN}

\section{Analisis Dan Desain Pembelajaran}

Pada tahap analisis tim peneliti mencoba terjun langsung dengan melakukan studi pendahuluan berupa wawancara, pada guru sejarah yang bersangkutan yaitu Ibu Diana Saraswati (27th). Berdasarkan wawancara yang dilakukan diperoleh informasi bahwa terkadang dalam pelajaran sejarah siswa merasa jenuh, apalagi siswa kelas $\mathrm{X}$ adalah masa peralihan dari tingkat SLTP ke SLTA. Butuh waktu penyesuaian untuk memahami karakter siswa. Pembelajaran di SLTA bagi siswa kelas $\mathrm{X}$, yang baru berjalan beberapa minggu membuat mereka seperti kaget akan sistem belajar yang memaksa siswa mencari tahu langsung sumber belajarnya. Sehingga dalam pembelajaran sejarah perlu memanfaatkan situs peninggalan megalitikum sebagai sumber belajar. Berikut ini adalah desain dan sintak 
kegiatan pembelajaran dengan dasar tipologi hasil budaya praaksara di memanfaatan situs peninggalan sejarah Indonesia di lingkungan terdekat: sebagai sumber belajar pada kompetensi

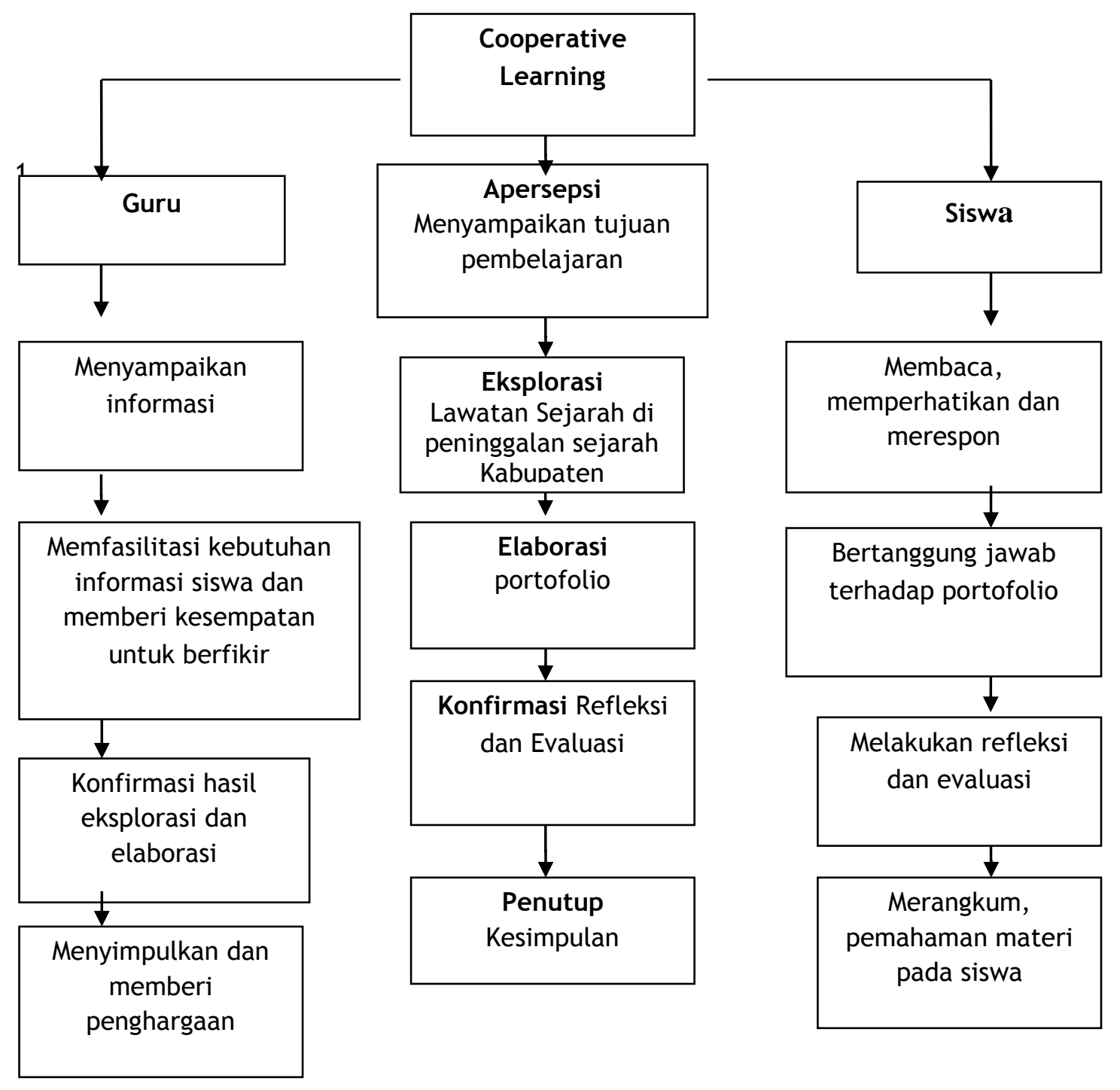

Gambar 2. Desain Pembelajaran yang direncakan

Tabel 1: Sintak Kegiatan Pembelajaran Pra Siklus

\begin{tabular}{|l|l|l|c|}
\hline \multicolumn{1}{|c|}{ Kegiatan Guru } & \multicolumn{1}{|c|}{ Tahap } & Kegiatan Peserta Didik & Waktu \\
\hline $\begin{array}{l}\text { Memeriksa kehadiran, } \\
\text { kebersihan dan kerapian } \\
\text { kelas } \\
\text { Menjelaskan Kompetensi } \\
\text { Dasar }\end{array}$ & Apersepsi & $\begin{array}{l}\text { Siswa mendengarkan } \\
\text { penjelasan guru }\end{array}$ & 5 menit \\
\hline - Menjelaskan tujuan & Fase 1: & $\bullet$ Memperhatikan & 10 \\
\hline
\end{tabular}




\begin{tabular}{|c|c|c|c|}
\hline $\begin{array}{ll}\text { pembelajaran } \\
\text { - Menjelaskan bahwa } \\
\text { pembelajaran sejarah } \\
\text { menggunakan media power } \\
\text { point }\end{array}$ & $\begin{array}{ll}\text { - } & \text { Menyampaikan } \\
\text { tujuan } \\
\text { pembelajaran }\end{array}$ & penjelasan guru & menit \\
\hline $\begin{array}{l}\text { Menyampaikan informasi } \\
\text { secara singkat mengenai } \\
\text { hasil budaya pra aksara }\end{array}$ & \begin{tabular}{|l} 
Eksplorasi \\
Fase 2: \\
- Menyampaikan \\
informasi
\end{tabular} & 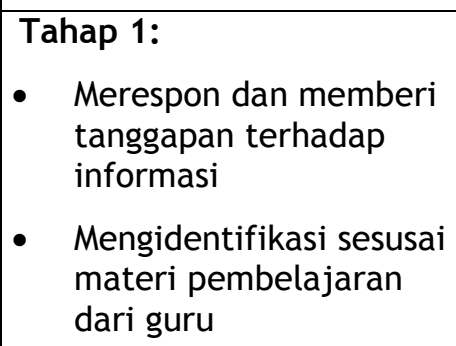 & $\begin{array}{c}30 \\
\text { menit }\end{array}$ \\
\hline $\begin{array}{l}\text { - Memfasilitasi siswa dengan } \\
\text { materi dari power point } \\
\text { untuk mengetahui } \\
\text { kemampuan awal siswa } \\
\text { - Memberi kesempatan untuk } \\
\text { berfikir, menganalisis, } \\
\text { menyelesaikan masalah, dan } \\
\text { bertindak tanpa rasa takut }\end{array}$ & $\begin{array}{l}\text { Elaborasi } \\
\text { Fase 3: } \\
\text { - } \quad \text { Post Test }\end{array}$ & $\begin{array}{l}\text { Tahap 2: } \\
\text { - } \quad \text { Setiap siswa } \\
\text { mengerjakan lembar } \\
\text { kerja siswa dengan } \\
\text { pengetahuan awal } \\
\text { tentang budaya pra } \\
\text { aksara } \\
\text { Tahap 3: } \\
\text { - Setiap kelompok } \\
\text { menyimpulkan materi } \\
\text { tugas dan menyerahkan } \\
\text { kepada guru }\end{array}$ & $\begin{array}{c}20 \\
\text { menit }\end{array}$ \\
\hline $\begin{array}{l}\text { - Memberikan umpan balik } \\
\text { positif dan penguatan dalam } \\
\text { bentuk lisan } \\
\text { - Memberikan konfirmasi dan } \\
\text { refleksi terhadap hasil } \\
\text { eksplorasi dan elaborasi } \\
\text { - Memberikan evaluasi untuk } \\
\text { mengukur pemahaman dan } \\
\text { prestasi siswa }\end{array}$ & $\begin{array}{l}\text { Konfirmasi } \\
\text { Fase 4: } \\
\text { - } \quad \text { Refleksi } \\
\text { - } \quad \text { Evaluasi }\end{array}$ & $\begin{array}{l}\text { Tahap 4: } \\
\text { - } \quad \text { Melakukan refleksi dan } \\
\text { bersama-sama } \\
\text { mengenai hasil } \\
\text { pemahaman materi } \\
\text { siswa } \\
\text { - } \quad \text { Melakukan evaluasi }\end{array}$ & $\begin{array}{c}15 \\
\text { menit }\end{array}$ \\
\hline $\begin{array}{ll} & \text { Bersama-sama siswa } \\
& \text { menyimpulkan materi }\end{array}$ & $\begin{array}{l}\text { Penutup } \\
\text { Fase 5: }\end{array}$ & $\begin{array}{l}\text { Tahap 5: } \\
\text { - } \quad \text { Bersama-sama guru } \\
\text { menyimpulkan materi } \\
\text { Peninggalan pra aksara }\end{array}$ & $\begin{array}{c}10 \\
\text { menit }\end{array}$ \\
\hline
\end{tabular}

Tabel 2: Sintak Kegiatan Pembelajaran Siklus I dan II

\begin{tabular}{|l|c|c|c|}
\hline \multicolumn{1}{|c|}{ Kegiatan Guru } & Tahap & Kegiatan Peserta Didik & Waktu \\
\hline $\begin{array}{l}\text { Guru mengajak siswa } \\
\text { mengunjungi situs } \\
\text { megalitikum di Kabupaten } \\
\text { Bondowoso } \\
\text { Menjelaskan Kompetensi } \\
\text { Dasar }\end{array}$ & Apersepsi & $\begin{array}{l}\text { Siswa mendengarkan } \\
\text { penjelasan guru }\end{array}$ & $\begin{array}{c}10 \\
\text { menit }\end{array}$ \\
\hline
\end{tabular}




\begin{tabular}{|c|c|c|c|}
\hline $\begin{array}{ll}\text { - } & \text { Menjelaskan tujuan } \\
\text { pembelajaran } \\
\text { - } \\
\text { Menjelaskan bahwa } \\
\text { pembelajaran sejarah } \\
\text { tidak hanya menggunakan } \\
\text { model konvensional } \\
\text { tetapi bisa juga } \\
\text { menggunakan lawatan } \\
\text { sejarah }\end{array}$ & $\begin{array}{l}\text { Fase 1: } \\
\text { - } \quad \text { Menyampaikan } \\
\text { tujuan } \\
\text { pembelajaran }\end{array}$ & 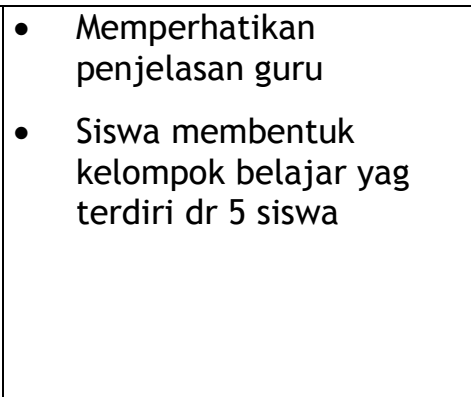 & $\begin{array}{c}10 \\
\text { menit }\end{array}$ \\
\hline $\begin{array}{l}\text { - Menyampaikan informasi } \\
\text { mengenai peninggalan } \\
\text { hasil budaya situs } \\
\text { megalitikum }\end{array}$ & \begin{tabular}{|l}
\multicolumn{2}{c}{ Eksplorasi } \\
Fase 2: \\
- $\begin{array}{l}\text { Menyampaikan } \\
\text { informasi }\end{array}$ \\
- Menjelaskan \\
berbagai \\
peninggalan \\
sejarah situs \\
megalitikum \\
dibantu dengan \\
penjaga situs
\end{tabular} & $\begin{array}{l}\text { Tahap 1: } \\
\text { - } \quad \text { Merespon dan memberi } \\
\text { tanggapan terhadap } \\
\text { informasi } \\
\text { - } \\
\text { Mengidentifikasi } \\
\text { peninggalan megalitikum } \\
\text { sesuai kelompok siswa } \\
\text { yang telah terbagi }\end{array}$ & $\begin{array}{c}90 \\
\text { menit }\end{array}$ \\
\hline $\begin{array}{l}\text { - Memfasilitasi kelompok } \\
\text { siswa untuk mencatat dan } \\
\text { memahami langsung } \\
\text { peninggalan sejarah } \\
\text { dengan pengambilan } \\
\text { dokumentasi } \\
\text { - Memberi kesempatan } \\
\text { untuk berfikir, } \\
\text { menganalisis, } \\
\text { menyelesaikan masalah }\end{array}$ & $\begin{array}{l}\text { Elaborasi } \\
\text { Fase 3: } \\
\text { - } \quad \text { Penyampaian } \\
\text { informasi dari guru } \\
\text { dan penjaga situs }\end{array}$ & $\begin{array}{l}\text { Tahap 2: } \\
\text { - } \quad \text { Setiap kelompok } \\
\text { membuat tugas materi } \\
\text { kelompoknya dan } \\
\text { mendokumentasikan } \\
\text { secara langsung melalui } \\
\text { pengklasifikasian } \\
\text { peninggalan sejarah dan } \\
\text { pembuatan video untuk } \\
\text { sumber belajar siswa } \\
\\
\text { Tahap 3: } \\
\text { - Setiap kelompok } \\
\text { menyelesaikan tugas } \\
\text { materi kelompoknya dan } \\
\text { menyerahkan kepada } \\
\text { guru pada pertemuan } \\
\text { selanjutnya }\end{array}$ & $\begin{array}{c}60 \\
\text { menit }\end{array}$ \\
\hline 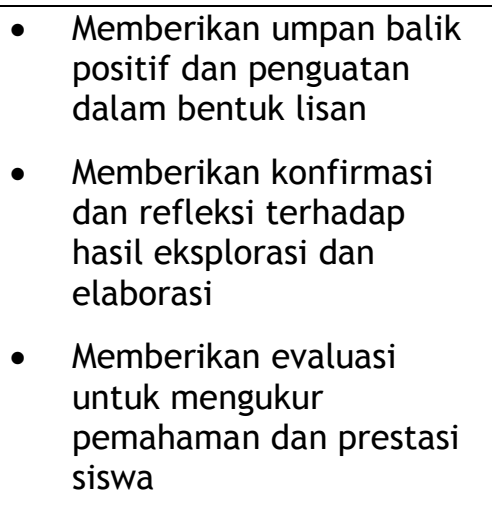 & $\begin{array}{l}\text { Konfirmasi } \\
\text { Fase 4: } \\
\text { - } \quad \text { Refleksi } \\
\text { - } \quad \text { Evaluasi }\end{array}$ & $\begin{array}{l}\text { Tahap 4: } \\
\text { - } \quad \text { Melakukan refleksi dan } \\
\text { bersama-sama } \\
\text { Melakukan evaluasi }\end{array}$ & $\begin{array}{c}15 \\
\text { menit }\end{array}$ \\
\hline
\end{tabular}




\begin{tabular}{|c|c|c|c|}
\hline $\begin{array}{ll} & \text { Bersama-sama siswa } \\
& \text { menyimpulkan materi }\end{array}$ & \begin{tabular}{|l} 
Penutup \\
Fase 5:
\end{tabular} & 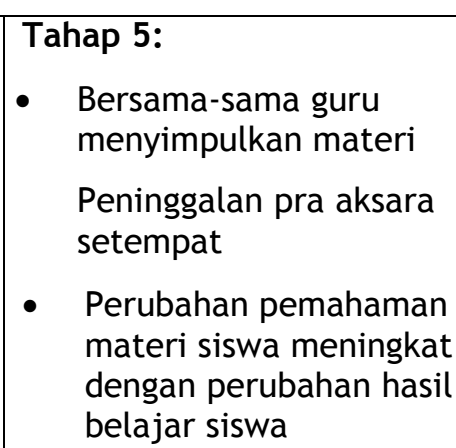 & $\begin{array}{c}10 \\
\text { menit }\end{array}$ \\
\hline
\end{tabular}

Dalam perumusan desain pembelajaran dan sintak ini disesuaikan dengan kondisi guru, siswa dan sekolah yang dirasa mampu untuk mengikuti kegiatan pembelajaran dengan model lawatan sejarah dengan tujuan pemahaman siswa dengan meningkatkan hasil belajar siswa.

\section{Development}

Development adalah proses pengembangan booklet yang akan digunakan siswa dalam melaksanakan lawatan sejarah. Adanya bantuan booklet berisi tentang jenis-jenis peninggalan pra aksara sangat membantu siswa selama melakukan studi lapangan mengunjungi situs pra aksara di Kabupaten Bondowoso. Booklet yang disusun telah diuji oleh ahli sejarah yaitu Bapak Adzkiyak, SS, MA melalui 1 kali revisi kesesuaian tulisan dan warna. Menurut Bapak Adzkiyak, booklet ini sudah layak dijadikan bahan ajar siswa sebagai pedoman di lapangan karena sesuai dengan materi yang digunakan yaitu tentang peninggalan pra aksara sehingga siswa mampu menjadikan booklet sebagai bahan ajar mereka di lapangan.

\section{Implementasi}

Setelah melakukan kegiatan pembelajaran pendahuluan sesuai dengan kondisi kelas dan kegiatan belajar direncanakan 2 sklis yaitu siklus 1 dan siklus 2 dengan rentang waktu sesuai dengan kegiatan belajar di sekolah pada tiap pertemuannya.

Penelitian ini dirancang menjadi tiga siklus, setiap siklus terdiri dari empat tahapan Perencanaan (planning), pelaksanaan/pemberian tindakan (action), pengamatan (observation) dan refleksi (refleksion).

1. Rencana Tindakan Siklus I

a. Perencanaan tindakan siklus I

1) Membuat Rencana Pelaksaan Pembelajaran (RPP) Kompetensi Dasar: Memahami sejarah, kenampakan alam dan keragaman suku bangsa di lingkungan kabupaten/ kota dan provinsi. Kompetensi Dasar: Menganalisis berdasarkan tipologi hasil budaya pra aksara di Indonesia termasuk yang berada di lingkungan terdekat. 
RPP ini untuk 1 siklus $(2 x$

Pertemuan atau $2 \times 45$ menit).

2) Mempersiapkan metode pembelajaran sesuai dengan kebutuhan pada setiap pertemuan.

3) Menyiapkan tugas untuk langkah evaluasi pertemuan yang bersangkutan

4) Merancang dan menyiapkan alat evaluasi untuk megukur ketercapaian tujuan pembelajaran pada setiap pertemuan

b. Pelaksanaan tindakan siklus I

1) Guru memberikan apersepsi tentang peninggalanpeninggalan sejarah yang ada di lingkungan setempat

2) Siswa dibentuk menjadi 1 kelompok lima siswa.

3) Guru mengajak siswa untuk lawatan sejarah mengunjungi situs peninggalan sejarah dengan memberi booklet pada masing-masing siswa sebagai panduan selama melakukan lawatan sejarah.

4) Guru dibantu penjaga situs menjelaskan berbagai macam peninggalan pra-aksara yang terdapat di situs Pakauman.
5) Siswa dibimbing mengidentifikasi peninggalan pra aksara situs.

6) Guru memberikan tugas untuk pertemuan berikut

c. Observasi siklus I

1) Observer mengamati proses pembelajaran dengan sub pokok bahasan peninggalan pra aksaradi lingkungan setempat

2) Observer mengamati sikap dan tingkah laku siswa selama pembelajaran berlangsung

3) Observer menganalisis hasil pengamatan aktivitas siswa dan kerja siswa melalui hasil portofolio siswa melalui lembar kerja siswa maupun lembar evaluasi yang lain.

d. Refleksi siklus I

Hasil pengamatan dianalisis untuk memperoleh gambaran bagaimana dampak dari tindakan yang dilakukan, hal apa saja yang perlu diperbaiki dan apa saja yang harus diperbaiki serta apa saja yang harus menjadi perhatian pada tindakan berikutnya. Siklus ini diakhiri dengan uji soal sikus I.

2. Refleksi Siklus I

Hasil pengamatan dianalisis untuk melihat atau memperoleh gambaran apakah dengan penggunaan cerita rakyat bergambar memiliki dampak perubahan terhadap 
siswa (baik nilainya maupun tingkah lakunya) juga hal apa saja yang perlu diperbaiki dan menjadi perhatian pada tindakan berikutnya. Siklus 1 ini diakhiri dengan uji soal. Apabila pada siklus I ini kurang berhasil atau belum memnuhi kriteria keberhasilan maka peneliti harus merancang kembali komponen sintak untuk siklus selanjutnya.

Untuk mengukur tingkat pemahaman siswa digunakan angket yang diisi oleh siswa kelas X IIS sejumlah 30 orang siswa.

Sedangkan untuk mengukur pembelajaran siswa, digunakan soal pretest pada siswa sehingga hasil pembelajaran awal sudah terlihat saaat pembelajaran pertama kali dilaksankan di kelas X IIS. Kemudian untuk menerapkan pembelajaran dengan memanfaatkan situs

peninggalan sejarah pada siklus I dan siklus Il digunakan soal post-tes dan lembar kerja portofolio.

\section{Evaluasi}

Pada tahap evaluasi hasil yang dicapai yakni (1) perencanaan pembelajaran dimulai dengan kesiapan guru sejarah dengan kesesuaian materi dan kondisi kelas (2) penilaian dari tim peneliti sebagai observer dan rekan sejawat guru sejarah SLTA oleh Bapak Febri Kurniawan, S.Pd (3) assessment penerapan pembelajaran yang dilakukan oleh guru berdasar sintak dan RPP yang telah disiapkan. Adapun keberhasilah yang dicapai oleh siswa dapat dilihat dari perhitungan berikut:

\section{Tabulasi Hasil Pre-test dan Postest}

Dilihat dari hasil belajar siswa diperoleh hasil tabulasi hasil pre-test dan posttest yaitu

Tabel3: Paired Samples t test (rerata)

\begin{tabular}{|c|l|l|l|l|}
\hline & Mean & $\mathrm{N}$ & Std. Deviation & Std. Error Mean \\
\hline $\begin{array}{c}\text { Pair 1 pretes } \\
\text { postes }\end{array}$ & 60.0000 & 30 & 9,09178 & 1.66091 \\
& 86.6667 & 30 & 7.80510 & 1.42501 \\
\hline
\end{tabular}

Pada output ini diperlihatkan hasil ringkasan statistik diskriptif dari kedua sampel atau data pretest dan postes. Dimana rata-rata dari nilai pretes yang diperoleh oleh siswa yakni 60,00 sedangkan rata-rata nilai posttes yang diperoleh oleh siswa yaitu 86,66 . Terlihat meningkat dari rata-rata pada 30 siswa dimana pada pra siklus saat pembelajaran didalam kelas nilai rata-rata pada siswa hanya 60,83 kemudian setelah ada tindakan menggunakan lawatan sejarah pada siklus I terdapat peningkatan menjadi 67, akan tetapi tingkat keberhasilan belum bisa dicapai karena rata-rata nilai siswa harus diatas 75. Pada siklus ke II baru terlihat 
tingkat keberhasilannya dengan rerata 86,7 yang mengartikan bahwa keberhasilan baru dicapai pada siklus ke II.

2. Uji Efektivitas

Uji efektivitas ini digunakan untuk menggunakan SPSS, keefektifan pembelajaran dapat dinilai dan menjadi buktian keberhasilan belajar siswa di kelas. Adapun hasil uji efektivitas adalah sebagai berikut:

Tabel 4: Uji Efektifitas

\begin{tabular}{|c|c|c|c|c|c|c|c|c|c|}
\hline & & \multicolumn{5}{|c|}{ Paired Differences } & \multirow[t]{3}{*}{$\mathrm{t}$} & \multirow[t]{3}{*}{$\mathrm{df}$} & \multirow{3}{*}{$\begin{array}{c}\text { Sig. } \\
(2- \\
\text { tailed } \\
\quad\end{array}$} \\
\hline & & \multirow[t]{2}{*}{ Mean } & \multirow[t]{2}{*}{$\begin{array}{c}\text { Std. } \\
\text { Deviation }\end{array}$} & \multirow[t]{2}{*}{$\begin{array}{l}\text { Std. } \\
\text { Error } \\
\text { Mean }\end{array}$} & \multicolumn{2}{|c|}{$\begin{array}{l}95 \% \text { Confidence } \\
\text { Interval of the } \\
\text { Difference }\end{array}$} & & & \\
\hline & & & & & Lower & Upper & & & \\
\hline Pair 1 & $\begin{array}{l}\text { Pretes- } \\
\text { Postes }\end{array}$ & $-26,66$ & 11,6943 & 2,13527 & $\begin{array}{c}- \\
31,033 \\
79\end{array}$ & $\begin{array}{c}- \\
22.2995 \\
4\end{array}$ & $\begin{array}{c}- \\
12,489\end{array}$ & 29 & .000 \\
\hline
\end{tabular}

\section{Dasar Pengambilan Keputusan}

1. Jika nilai Sig. (2-tailed) <0,05, maka terdapat perbedaan yang signifikan antara hasil belajar pada data pretes dan postes.

2. Jika nilai Sig.(2-tailed) $>0,05$ maka tidak terdapat perbedaan yang signifikan antara hasil belajar pada data pretes dan posttes.

\section{Pengambilan Keputusan}

Diketahui bahwa nilai Sig.(2-tailed) sebesar $0,000<0,05$, maka dapat disimpulakan bahwa terdapat perbedaan yang nyata antara hasil belajar sejarah pada data pretest dan posttes. Jadi dapat disimpulkan pula, bahwa metode lawatan sejarah dengan memanfaatkan situs peninggalan sejarah sebagai sumber belajar siswa kelas X IIS SMA Negeri 2 Bondowso dapat meningkatkan hasil belajar sejarah yang diperoleh masingmasing siswa.

Dari hasil SPSS diatas kemudian dilakukan uji efektivitas metode hasil lawatan sejarah dengan hasilnya, yaitu:

\begin{tabular}{llll}
\hline $\begin{array}{l}\text { Rata- } \\
\text { rata } \\
X 1\end{array}$ & $\begin{array}{l}\text { Rata-rata } \\
\text { X2 }\end{array}$ & $\Sigma(X 1) 2$ & $\Sigma(X 2) 2$ \\
\hline 60 & 86,66666667 & 110400 & 227100 \\
\hline
\end{tabular}

$$
t=\frac{X_{1}-X_{2}}{\sqrt{\left(\frac{\sum x_{1}^{2}+\sum x_{2}^{2}}{n_{1}+n_{2}-2}\right)\left(\frac{1}{n_{1}}+\frac{1}{n_{2}}\right)}}
$$




$$
\begin{aligned}
& =\frac{60-86,66}{\sqrt{\left(\frac{110400+22700}{30+30-2}\right)\left(\frac{1}{30}+\frac{1}{30}\right)}} \\
& =1,453
\end{aligned}
$$

Dari data yang telah dilakukan diketahui bahwa pembelajaran sejarah dengan memanfaatkan situs peninggalan sejarah Kabupaten Bondowoso terlihat efektif menigkatkan hasil belajar sejarah siswa kelas $X$ IIS di SMA Negeri 2 Bondowoso.

\section{Tabulasi Hasil Angket}

Berdasar hasil angket setelah melakukan lawatan sejarah didapat data dengan sebaran 20 butir pertanyaan pada 30 siswa. Hasil rerata sebagaran angket adalah:

Tabel 5: rerata hasil sebaran angket

\begin{tabular}{|l|l|}
\hline Responden & Jumlah \\
\hline 30 & 2616 \\
\hline Rata-rata & 87,2 \\
\hline
\end{tabular}

Dari hasil analisis data yang telah didapatkan, nilai hasil belajar siswa meningkat dimana saat pra siklus terlihat nilai rerata siswa adalah 60,83 kemudia di sklus I nilai rerata adalah 67 dimana nilai tersebut masih kurang dan baru terpenuhi setelah siklus ke III dengan nilai 86,7. Pemahaman siswa setelah penilaian angket dengan rata-rata 87,2 dan menunjukkan angka pemahaman diatas rata-rata. Hasil belajar dan pemahaman siswa mengalami peningkatan setelah melakukan pembelajaran dengan menggunakan lawatan sejarah pada situs peninggalan sejarah tertinggal di Kabupaten Bondowoso melalui media booklet yang berisikan materi peninggalan situs megalitikum.

\section{PENUTUP}

\section{Simpulan}

Pembelajaran sejarah dengan menggunakan metode lawatan sejarah yang dimulai dengan melihat kondisi pembelajaran sebelumnya di dalam kelas menggunakan hasil posttest, terlihat siswa kurang bergairah mengikuti pelajaran karena dianggap membosankan.

Siswa hanya bisa membayangkan saja bagaimana kehidupan pra aksara dari gambar power point yang dipaparkan guru. Kemudian, setelah dilakukan lawatan sejarah pada situs megalitikum di Kabupaten Bondowoso, rasa antusias siswa terlihat sekali dari awal pembelajaran dan selama kegiatan lawatan sejarah berlangsung. Pemahaman siswa terlihat dari cara siswa menjawab secara spontan dari beberapa pertanyaan penjelasan guru mengenai hasil peninggalan sejarah pada masa praaksara. Pemahaman selanjutnya dapat dilihat dari cara siswa mengerjakan lembar pertanyaan dan portofolio dengan rasa bersemangat dan tanpa rasa kebingungan seperti awal pembelajaran di kelas.

\section{Saran}

1) Guru dapat memebrikan inovasi pembelajaran tanpa harus meninggalkan metode konvensional 
sepenuhnya salah satunya dengan mengadakan lawatan sejarah di sekitar tempat tinggal.

2) Dinas Purbakala lebih memperhatikan peninggalan sejarah dengan merawat dan memberikan akses mudah pada pihak dinas ataupun sekolah dengan memberikan promosi sebagai salah satu wisata edukasi pemerintak Kabupatern Bondowoso.

\section{DAFTAR PUSTAKA}

Alfian, M. 2011. Pendidikan Sejarah Dan Permasalahan Yang Dihadapi. Dalam Khazanah Pendidikan: Jurnal IImiah Pendidikan Vol. III No. 2

Ananda, I.W dkk. 2013. Manajemen AstaKosala Kosali Candi Purasada, Desa Adat Kapal, Kecamatan Mengwi, Kabupaten Badung, Bali (Perspektif Lokal Genius dan Pemanfaatan Sebagai Sumber Belajar Sejarah) Bagi Siswa Kelas XI IPS SMA Negeri 2 Tabanan. Dalam Jurnal Program Pascasarjana Universitas Pendidikan Ganesha Vol. 4 No. 1
Arikunto, S, dkk. 2014. Penelitian Tindakan Kelas. Cetakan kedua belas. Jakarta: Bumi Aksara.

Ayatrohaedi. 1981. Kamus Istilah Arkeologi. Jakarta: Pusat Pembinaan dan Pengembangan Bahasa, Departemen Pendidikan dan Kebudayaan.

Hidayat, Muhamad. 2007. Menengok Kembali Budaya dan Masyarakat Megalitik Bondowoso. Dalam Jurnal Berkala Arkeologi Vol. 27 No. 1

Kurniawan, Febri. 2008. Eksplorasi Potensi Situs Pakauman Kecamatan Grujugan Kabupaten Bondowoso Sebagai Objek Wisata Sejarah Dan Budaya. Skripsi, Tidak Dipublikasikan. Jember: FKIP Universitas Jember.

Mashoed. 2004. Sejarah dan Budaya Bondowoso. Surabaya: Papyrus.

Permendikbud Kurikulum 2013 No. 59 Tahun 2014 Tentang Kerangka Dasar Kurikulum Sekolah Menengah Atas. Di Akses Tanggal 5 Maret 2016.

Purnamasari, lin dan Wasino. 2011. Pengembangan Model Pembelajaran Sejarah Berbasis Situs Sejarah Lokal di SMA Negeri Temanggung. Dalam Jurnal Paramita Historical Studies Vol. 21 No. 2 